\title{
Lateral Hypothalamus GABAergic Neurons Modulate Consummatory Behaviors Regardless of the Caloric Content or Biological Relevance of the Consumed Stimuli
}

\author{
Montserrat Navarro ${ }^{1,2}$, Jeffrey J Olney ${ }^{1,2}$, Nathan W Burnham ${ }^{1,2}$, Christopher M Mazzone ${ }^{2,3}$, \\ Emily G Lowery-Gionta ${ }^{2,3}$, Kristen E Pleil ${ }^{2,3}$, Thomas L Kash ${ }^{2,3}$ and Todd E Thiele ${ }^{*, 1,2}$ \\ 'Department of Psychology and Neuroscience, University of North Carolina, Chapel Hill, NC, USA; ${ }^{2}$ Bowles Center for Alcohol Studies, University of \\ North Carolina, Chapel Hill, NC, USA; ${ }^{3}$ Department of Pharmacology, University of North Carolina, Chapel Hill, NC, USA
}

\begin{abstract}
It was recently reported that activation of a subset of lateral hypothalamus (LH) GABAergic neurons induced both appetitive (food-seeking) and consummatory (eating) behaviors in vGat-ires-cre mice, while inhibition or deletion of GABAergic neurons blunted these behaviors. As food and caloric-dense liquid solutions were used, the data reported suggest that these LH GABAergic neurons may modulate behaviors that function to maintain homeostatic caloric balance. Here we report that chemogenetic activation of this GABAergic population in vGat-ires-cre mice increased consummatory behavior directed at any available stimulus, including those entailing calories (food, sucrose, and ethanol), those that do not (saccharin and water), and those lacking biological relevance (wood). Chemogenetic inhibition of these neurons attenuated consummatory behaviors. These data indicate that LH GABAergic neurons modulate consummatory behaviors regardless of the caloric content or biological relevance of the consumed stimuli.

Neuropsychopharmacology (2016) 4I, I505-1512; doi:I0.1038/npp.20I5.304; published online 28 October 2015
\end{abstract}

\section{INTRODUCTION}

Numerous points of evidence spanning many years have implicated the lateral hypothalamus (LH) in modulating the consumption of rewarding stimuli. The LH was originally implicated in modulating feeding behavior by evidence demonstrating that lesions of the LH reduced food consumption while electrical stimulation of this region promoted food intake (Anand and Brobeck, 1951; Delgado and Anand, 1953). It was later shown that rodents will work for electrical stimulation of $\mathrm{LH}$ neurons in proportion to their energy balance (Hoebel and Teitelbaum, 1962; Hoebel and Thompson, 1969), direct evidence that the LH is critical in reward-seeking behaviors. Since these original observations, research has shown that the LH not only modulates consummatory behaviors directed at natural rewards, such as food and water, but is also a critical region in supporting the consumption of drugs, including ethanol (Leibowitz, 2007; Sprow et al, 2015). In fact, the LH is often considered to be a key player woven into proposed reward neurocircuitry, which also includes the mesolimbic dopaminergic system

*Correspondence: Dr TE Thiele, Department of Psychology, University of North Carolina, Davie Hall, CB\#3270, Chapel Hill, NC 27599-3270, USA, Tel: + I 919966 1519, Fax: + I 9199622537

E-mail: thiele@unc.edu

Received 4 June 2015; revised 3 September 20I5; accepted I October 2015; accepted article preview online 7 October 2015 and the extended amygdala (Koob, 2003; Koob and Le Moal, 2001).

The role of GABAergic receptor signaling within the $\mathrm{LH}$ in modulating consummatory behaviors has been well studied using pharmacological approaches (Kelly et al, 1977; Turenius et al, 2009a,b). Although pharmacological approaches establish that GABA receptor signaling in the $\mathrm{LH}$ modulates consummatory behaviors, conclusions regarding the sources of GABA innervation, or the direct role of local GABAergic neurons, are not possible using traditional pharmacological approaches. Historically, direct manipulation of specific cell populations was challenging, but recently developed optogenetic and chemogenetic approaches allow one to achieve this goal. In one recent example, Jennings et al (2015) used a combination of optogenetic, chemogenetic, and neuronal ablation procedures to show that activation of LH GABAergic neurons increased, and inhibition or ablation of GABAergic neurons decreased, appetitive (food-seeking) and consummatory (eating) behaviors.

The stimulus rewards used in the experiments conducted by Jennings et al (2015) were either food or a caloric-dense liquid solution. As such, one interpretation of their data is that the LH GABAergic neurons under investigation regulate behaviors directed at maintaining caloric balance. To directly test this interpretation, we performed a series of studies utilizing a chemogenetic approach. Designer receptors exclusively activated by designer drugs (DREADDs) are genetically modified muscarinic receptors that have lost their 
affinity for endogenous acetylcholine but can be activated by an otherwise physiologically inert ligand, clozapine- $N$-oxide (CNO). DREADDs have been developed that are coupled through the $\mathrm{Gq}$ or $\mathrm{Gi}$ pathways to stimulate or inhibit neuronal activity, respectively (Armbruster et al, 2007). DREADDs are packaged in adeno-associated viral (AAV) vectors and have been made to be cre-inducible. Thus when combined with transgenic cre-line mice, one can target DREADDs to specific neuronal populations. In the present report, we injected DREADD viral vectors into the $\mathrm{LH}$ of vGat-ires-cre mice (Vong et al, 2011) to selectively express DREADDs on GABAergic neurons in the LH. Here we found that activation of LH GABAergic neurons increased consumption of any available stimulus, including those entailing calories (food, sucrose, and ethanol), those lacking calories (saccharin and water), and those lacking biological relevance.

\section{MATERIALS AND METHODS}

\section{Animals}

All mice used in the present work were transgenic VGat-irescre mice on a C57BL/6J genetic background obtained from Dr Bradford Lowell (Vong et al, 2011). Four cohorts of mice were used: Cohort 1 (14 male and 14 female mice), Cohort 2 (6 male and 8 female mice), Cohort 3 (11 male and 9 female mice), and Cohort 4 (15 male mice). Mice were individually housed in plastic cages located in a vivarium with an ambient temperature of approximately $22^{\circ} \mathrm{C}$ and reverse light/dark cycle with lights off at 10:00 hours. Food (IsoPro RMH 3000, Purina LabDiet, St Louis, MO) and water were available ad libitum except during testing (see below). All procedures used were in accordance with the National Institute of Health guidelines and were approved by the University of North Carolina Institutional Animal care and Use Committee.

\section{Surgery}

Mice were bilaterally microinjected with $0.5 \mu \mathrm{l} /$ side of purified and concentrated AAV into the $\mathrm{LH}$ or the zona incerta (ZI). For the LH surgeries, the following stereotaxic coordinates were used: $-1.2 \mathrm{~mm}$ posterior to bregma, $\pm 1.2 \mathrm{~mm}$ lateral to midline, and $-5.1 \mathrm{~mm}$ ventral to the skull surface. For the ZI surgeries, the stereotaxic coordinates were: $-1.2 \mathrm{~mm}$ posterior to bregma, $\pm 1.2 \mathrm{~mm}$ lateral to midline, and $-4.26 \mathrm{~mm}$ ventral to the skull surface. Details on the DREADD virus can be found in the Supplementary Section.

\section{Mouse Cohort 1: Binge-Like Ethanol Drinking, Food, and Water Consumption and Open-Field Locomotor Activity}

We used a 4-day 'drinking-in-the-dark' (DID) procedure with the first cohort of mice, an animal model of binge-like ethanol drinking which promotes high levels of ethanol that are associated with blood ethanol concentrations (BECs) in excess of $80 \mathrm{mg} / \mathrm{dl}$ in a 2-4-h testing period (Rhodes et al, 2005; Thiele and Navarro, 2014). Procedural details for the DID procedure have recently been described elsewhere
(Thiele et al, 2014). Briefly, on days $1-3$, beginning $3 \mathrm{~h}$ into the dark cycle, water bottles were removed from all cages and replaced with bottles containing a $20 \%$ (v/v) ethanol solution. Mice had $2 \mathrm{~h}$ of access to ethanol after which ethanol bottles were removed from cages and water bottles were replaced.

Before stereotaxic surgery was performed, all animals went through one 4-day DID cycle. Consumption data collected during this initial test allowed us to distribute the animals into three groups in such a way that baseline levels of ethanol intake were similar between groups: mice were given bilateral infusions into the LH (as described above) of the AAV8hSyn-DIO-hM3D(Gq)-mcherry) viral vector $(n=9)$, the AAV8-hSyn-DIO-hM4D(Gi)-mcherry viral vector $(n=10)$, or the AAV8-hSyn-DIO-mcherry viral vector $(n=9)$. For surgery, mice were anesthetized with a cocktail of Ketamine $(117 \mathrm{mg} / \mathrm{kg})$ and xylazine $(7.92 \mathrm{mg} / \mathrm{kg})$. After a 21-day recovery period to allow time for virus transduction, DID testing procedures were initiated. On days 1-3, mice were habituated to intraperitoneal (i.p.) injections $(5 \mathrm{ml} / \mathrm{kg}$ ) by giving injection of a $0.5 \%$ DMSO solution in isotonic saline (the vehicle for $\mathrm{CNO}$ ) just before ethanol access. The same schedule was followed on day 4, except that ethanol access was extended to $4 \mathrm{~h}$ and i.p. injections consisted of vehicle or $\mathrm{CNO}$ (3 $\mathrm{mg} / \mathrm{kg}$ in a $5 \mathrm{ml} / \mathrm{kg}$ injection volume). After the 4 -h consumption period in which consumption measures were recorded hourly, tail blood samples were collected from the tail vein of each animal. Blood samples were centrifuged, and $5 \mu \mathrm{l}$ of plasma were analyzed for BECs using the Analox Alcohol Analyzer (Analox Instruments USA, Lunenburg, MA). After 3 days of rest, mice were run through another 4day DID procedure as described above except mice were given an i.p. injection of the alternate solution (vehicle or $\mathrm{CNO}$ ) that they did not receive during the first DID test, constituting a Latin square experimental design.

After binge-like ethanol consumption testing, these same mice were used to assess the effects of LH GABAergic neuronal manipulation on food and water consumption. Mice were given an i.p. injection of vehicle or $\mathrm{CNO}$ in the same dose and volume described above, and then food measure were collected hourly over $4 \mathrm{~h}$ beginning $3 \mathrm{~h}$ into the dark cycle. Mice were injected with vehicle or CNO in a Latin square design, with approximately 1 week between injections. Over the next 2 weeks, this same approach was used to assess the effects of vehicle or CNO injection on water consumption over a 2 -h period beginning $3 \mathrm{~h}$ into the dark cycle. Finally, over the final 2 weeks the effects of vehicle or CNO injection on open-field activity were assessed over a 2 - $\mathrm{h}$ period beginning $3 \mathrm{~h}$ into the dark cycle. Mice were injected with both vehicle and CNO in a Latin square design, with each injection separated by 1 week. Mice were then perfused using a standard procedure in our laboratory (Navarro et al, 2008), and brains were section and slide mounted to verify the placement of viral vectors.

\section{Mouse Cohort 2: Binge-Like Saccharin and Sucrose Consumption}

Mice from cohort 2 were randomly distributed into two groups and given bilateral infusions into the $\mathrm{LH}$ of either the AAV8-hSyn-DIO-hM3D $(\mathrm{Gq})$-mcherry viral vector $(n=8)$ or the AAV8-hSyn-DIO-hM4D(Gi)-mcherry viral vector 
( $n=6$ ) using the same procedures described above. After a 3week recovery period, the effects of vehicle or CNO injection on consumption of saccharin $(0.15 \%)$ or sucrose $(3 \%)$ were assessed. The consumption procedures were identical to DID procedures described above, except water was replaced by saccharin or sucrose over a 2 -h test beginning $3 \mathrm{~h}$ into the dark cycle. A Latin square design was used such that each animal received both vehicle and $\mathrm{CNO}$ on separate test days separated by a week. Mice were first tested with the saccharin solution for the first 2 weeks and then with the sucrose over the next 2 weeks. Mice were then perfused to verify the placement of viral vectors.

Mouse Cohort 3: Binge-Like Ethanol Drinking and Food Intake Following GABAergic Neuronal Manipulations in the $\mathrm{ZI}$

DID and food intake procedures were identical to those outlined for mouse cohort 1 above. After a presurgery run through DID procedures, mice were distributed into three groups based on ethanol consumption as above and treated with one of the three viral vectors aimed at the ZI: AAV8hSyn-DIO-hM3D(Gq)-mcherry $(n=7)$, AAV8-hSyn-DIOhM4D(Gi)-mcherry $(n=7)$, or AAV8-hSyn-DIO-mcherry $(n=6)$. Mice were then tested for the effects of vehicle or $\mathrm{CNO}$ injections (presented in a Latin square design as above) on binge-like ethanol drinking and then food intake. Mice were then perfused to verify the placement of viral vectors.

\section{Mouse Cohort 4: Wood Gnawing Behavior}

Mice from cohort 4 were randomly distributed into two groups and given bilateral infusions into the $\mathrm{LH}$ of either the AAV8-hSyn-DIO-hM3D(Gq)-mcherry viral vector $(n=8)$ or the AAV8-hSyn-DIO-mcherry viral vector $(n=7)$ using the same procedures described above. Details on the wood gnawing test can be found in Supplementary Section.

\section{Statistical Analyses}

All data were analyzed using repeated-measure analysis of variance (ANOVA) with viral vector and sex (when appropriate) as between-subjects variables and vehicle $v s$ CNO treatment as a within-subjects factor. For clarity, only significant effects (main or interactions) are described in detail below. When main effects or interaction effects were significant, post-hoc comparisons, when necessary, were performed using Bonferroni-corrected $t$-tests. All data are presented as mean $\pm \mathrm{SEM}$, and significance was accepted at $p<0.05$ (two-tailed).

\section{RESULTS}

\section{Mouse Cohort 1: Binge-Like Ethanol Drinking, Food and Water Consumption, and Open-Field Locomotor Activity}

Results from the binge-like ethanol consumption study $(\mathrm{a}-\mathrm{c})$ and examples of AAV8-hSyn-DIO-mcherry (d), AAV8hSyn-DIO-hM3D(Gq)-mcherry (e), and AAV8-hSyn-DIO$\mathrm{hM} 4 \mathrm{D}(\mathrm{Gi})$-mcherry (f) virus expression in the $\mathrm{LH}$ are presented in Figure 1. A repeated-measures (CNO vs vehicle $\times$ virus condition $\times$ sex) ANOVA performed on the 2-h binge-like ethanol consumption data showed a significant main effect of virus condition $(\mathrm{F}(2,20)=7.33, p=0.004)$ and a significant $\mathrm{CNO}$ vs vehicle $\times$ virus condition interaction effect $(\mathrm{F}(2,20)=35.93, p<0.001)$. Interestingly, post-hoc tests comparing $\mathrm{CNO} v$ s vehicle treatment showed
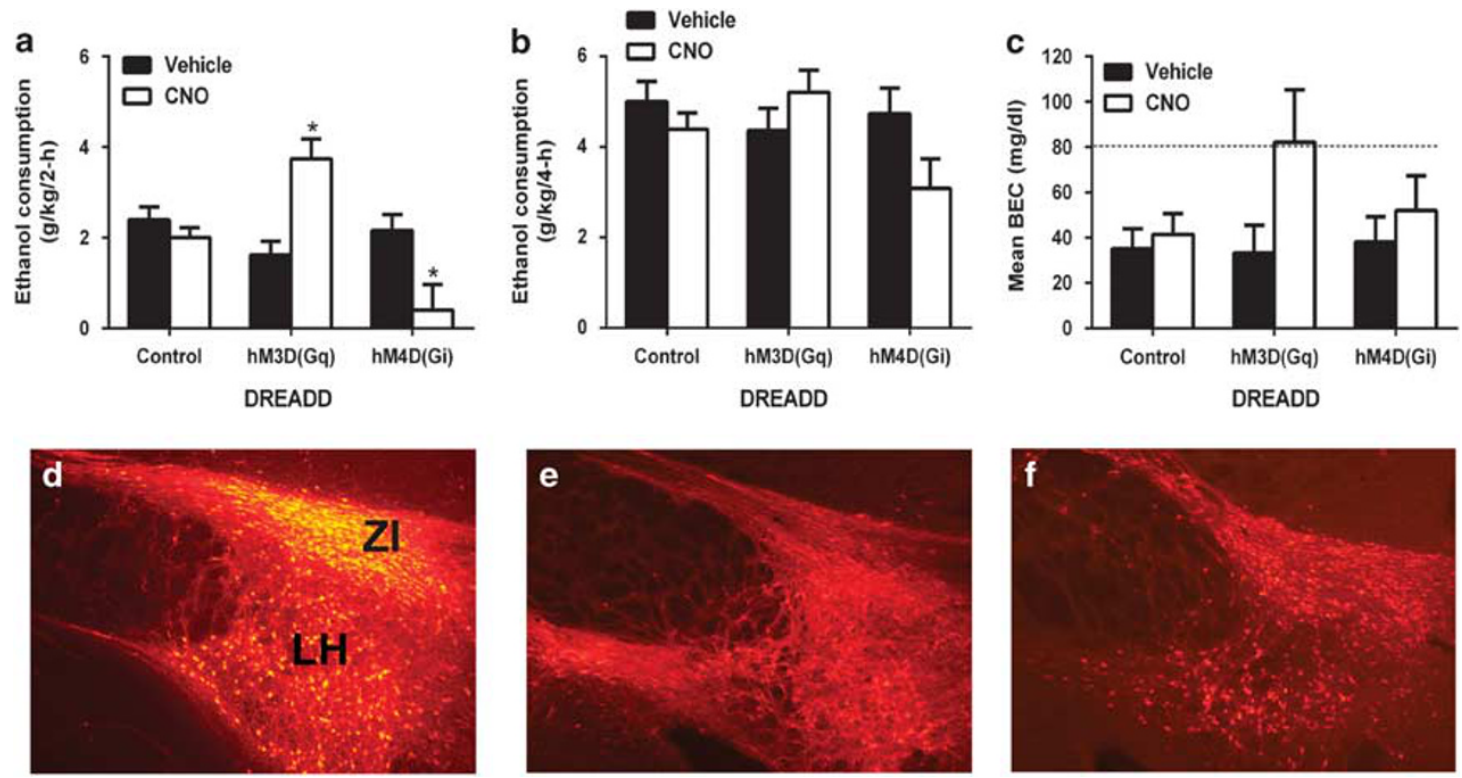

Figure I Results from the binge-like ethanol consumption study. Two- (a) and $4 \mathrm{~h}$ (b) binge-like ethanol (20\%, v/v) consumption and blood ethanol concentrations (BECs; c) and examples of AAV8-hSyn-DIO-mcherry (Control; d), AAV8-hSyn-DIO-hM3D(Gq)-mcherry (hM3D(Gq); e), and AAV8-hSyn$\mathrm{DIO}-\mathrm{hM} 4 \mathrm{D}(\mathrm{Gi})$-mcherry (hM4D(Gi); f) virus expression in the $\mathrm{LH}$. Relative to vehicle treatment, $\mathrm{CNO}$ significantly increased $2 \mathrm{~h}$ ethanol consumption, or reduced $2 \mathrm{~h}$ ethanol consumption, in the $\mathrm{hM} 3 \mathrm{D}(\mathrm{Gq})$ - or $\mathrm{hM} 4 \mathrm{D}(\mathrm{Gi})$-treated groups, respectively. All data are presented as mean $\pm \mathrm{SEM}$. $*$ Signifies $p<0.05$ relative to vehicle within each DREADD virus condition as determined by Bonferroni corrected t-tests (two-tailed). LH, lateral hypothalamus; Zl, zona incerta. 
a
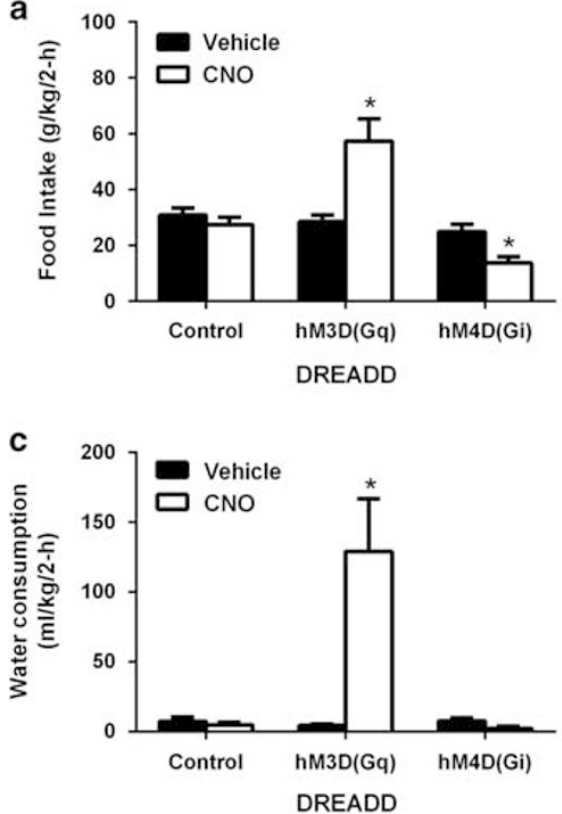

b
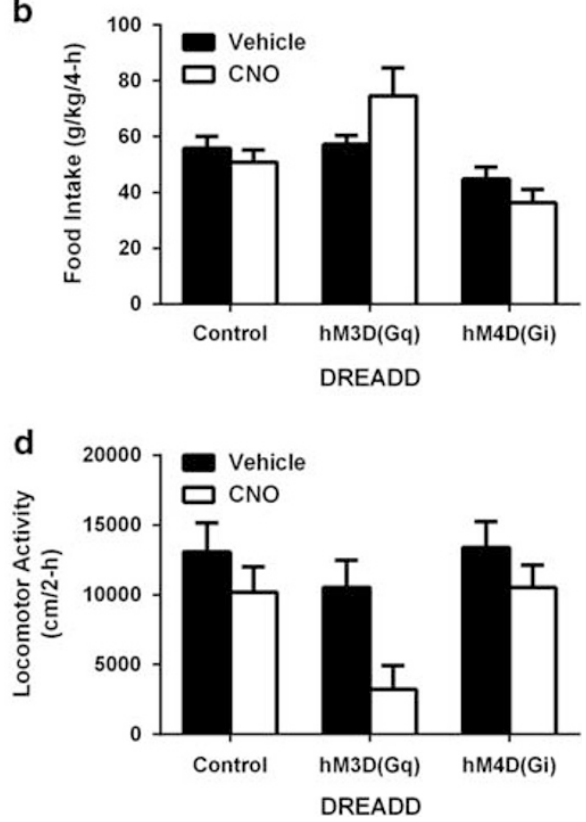

Figure 2 Results reflecting 2 (a) and $4 \mathrm{~h}$ (b) food intake, $2 \mathrm{~h}$ water consumption (c), and $2 \mathrm{~h}$ open-field locomotor activity assessment (d). Relative to vehicle treatment, CNO significantly increased $2 \mathrm{~h}$ food intake, or reduced $2 \mathrm{~h}$ ethanol consumption, in groups expressing $\mathrm{hM} 3 \mathrm{D}(\mathrm{Gq})$ or $\mathrm{hM} 4 \mathrm{D}(\mathrm{Gi})$ viruses in the $\mathrm{LH}$, respectively. Also relative to vehicle treatment $\mathrm{CNO}$ significantly increased water drinking in the hM3D(Gq) virus condition. All data are presented as mean \pm SEM. *Signifies $p<0.05$ relative to vehicle within each DREADD virus condition as determined by Bonferroni-corrected $t$-tests (two-tailed).

that CNO treatment significantly increased $2 \mathrm{~h}$ ethanol consumption in mice expressing the AAV8-hSyn-DIO-hM3D (Gq)-mcherry virus in the LH, while CNO treatment significantly blunted $2 \mathrm{~h}$ binge-like ethanol drinking in mice expressing the AAV8-hSyn-DIO-hM4D(Gi)-mcherry virus in the LH. There were no differences in binge-like ethanol drinking between vehicle and $\mathrm{CNO}$ treatment in mice expressing the control AAV8-hSyn-DIO-mcherry virus. A similar repeatedmeasures ANOVA run on the 4-h binge-like ethanol consumption data revealed a significant $\mathrm{CNO} v s$ vehicle $\times$ virus condition interaction effect $(\mathrm{F}(2,20)=4.58, p=0.023)$. Despite the significant interaction effect, post-hoc tests failed to reveal significant differences between the CNO- and vehicle-treated groups at any of the virus conditions. Finally, a repeatedmeasures ANOVA run on the BEC data revealed a significant CNO vs vehicle main effect $(\mathrm{F}(1,20)=4.98, p=0.037)$, but post-hoc tests failed to show a significant difference between the $\mathrm{CNO}-$ and vehicle-treated groups.

Data showing 2 (a) and $4 \mathrm{~h}$ (b) food intake, $2 \mathrm{~h}$ water consumption (c), and $2 \mathrm{~h}$ open-field locomotor activity (d) are depicted in Figure 2. A repeated-measures (CNO $v s$ vehicle $\times$ virus condition $\times$ sex) ANOVA run on 2 -h food intake data revealed a significant main effect of virus condition $(\mathrm{F}(2,21)=13.52, p<0.001)$ and a significant $\mathrm{CNO}$ vs vehicle $\times$ virus condition interaction effect $(F(2,21)=20.15$, $p<0.001)$. Post-hoc tests indicated that relative to vehicle, CNO significantly increased food intake, or reduced food intake in mice expressing the AAV8-hSyn-DIO-hM3D(Gq)mcherry or AAV8-hSyn-DIO-hM4D(Gi)-mcherry virus in the $\mathrm{LH}$, respectively. On the other hand, there was no effect of CNO vs vehicle treatment in mice expressing the AAV8hSyn-DIO-mcherry in the LH. A similar repeated-measures ANOVA run on 4-h food intake data revealed a main effect of virus condition $(\mathrm{F}(2,21)=6.36, p=0.007)$ and a significant $\mathrm{CNO}$ vs vehicle $\times$ virus condition interaction effect $(\mathrm{F}(2,21)=4.57, p=0.023)$. Post-hoc tests failed to reveal significant differences between the CNO- and vehicletreated groups at any of the virus conditions. A repeatedmeasures ANOVA run on 2-h water consumption data revealed main effects of $\mathrm{CON} v s$ vehicle condition $(\mathrm{F}(1,21)=79.15, p<0.001)$ and virus condition $(\mathrm{F}(2,21)=$ $71.43, p<0.001)$, and a significant interaction effect between CNO vs vehicle $\times$ virus condition variables $(\mathrm{F}(2,21)=96.78$, $p<0.001)$. Post-hoc tests run at each virus condition revealed that relative to vehicle treatment $\mathrm{CNO}$ significantly increased water drinking in mice expressing the AAV8-hSyn-DIO$\mathrm{hM} 3 \mathrm{D}(\mathrm{Gq})$-mcherry virus but did not alter water drinking at any of the other virus conditions. Finally, a repeatedmeasures ANOVA run on 2-h open-field locomotor activity data revealed significant main effects of $\mathrm{CNO} v s$ vehicle treatment condition $(\mathrm{F}(1,21)=9.21, p=0.006)$ and virus condition $(\mathrm{F}(2,21)=4.49, p=0.024)$, but the interaction between variables was not significant.

\section{Mouse Cohort 2: Binge-Like Saccharin and Sucrose Consumption}

Two hour saccharin (a) and sucrose (b) consumption are presented in Figure 3. A repeated-measures (CNO vs vehicle $\times$ virus condition $\times$ sex $)$ ANOVA performed on saccharin intake data revealed a significant main effect of virus condition $(\mathrm{F}(1,10)=6.44, p=0.03)$ and a significant $\mathrm{CNO} v s$ vehicle $\times$ virus condition interaction effect $(\mathrm{F}(1,10)=10.05, p=0.01)$. Post-hoc tests indicated that relative to vehicle treatment, treatment with $\mathrm{CNO}$ significantly increased saccharin intake or reduced saccharin intake in mice expressing the AAV8-hSyn-DIO-hM3D(Gq)-mcherry or AAV8-hSyn-DIO-hM4D(Gi)-mcherry virus in the $\mathrm{LH}$, 

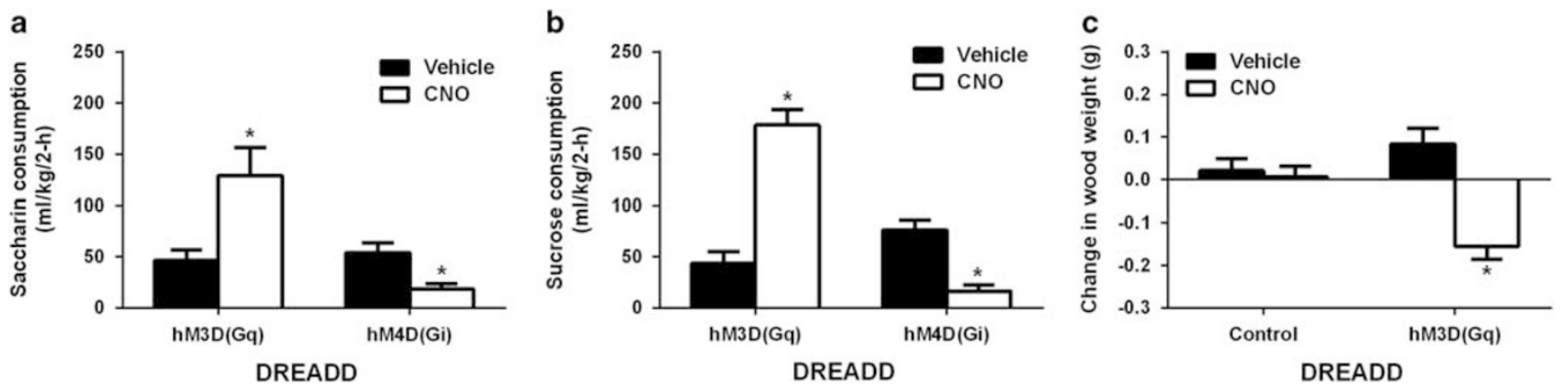

Figure 3 Results reflecting $2 \mathrm{~h} 0.15 \%(\mathrm{w} / \mathrm{v})$ saccharin (a), 3\% (w/v) sucrose (b) consumption testing, and the 2-h wood gnawing test (c). Relative to vehicle treatment, $\mathrm{CNO}$ significantly increased $2 \mathrm{~h}$ saccharin and sucrose intake, or reduced $2 \mathrm{~h}$ saccharin and sucrose intake, in groups expressing $\mathrm{hM} 3 \mathrm{D}(\mathrm{Gq})$ or $\mathrm{hM} 4 \mathrm{D}(\mathrm{Gi})$ viruses in the $\mathrm{LH}$, respectively. Further, CNO significantly increased wood gnawing (reflected as a reduction of wood weight) specifically in the group expressing the $\mathrm{hM} 3 \mathrm{D}(\mathrm{Gq})$ virus. All data are presented as mean \pm SEM. * Signifies $p<0.05$ relative to vehicle within each DREADD virus condition as determined by Bonferroni-corrected $t$-tests (two-tailed).
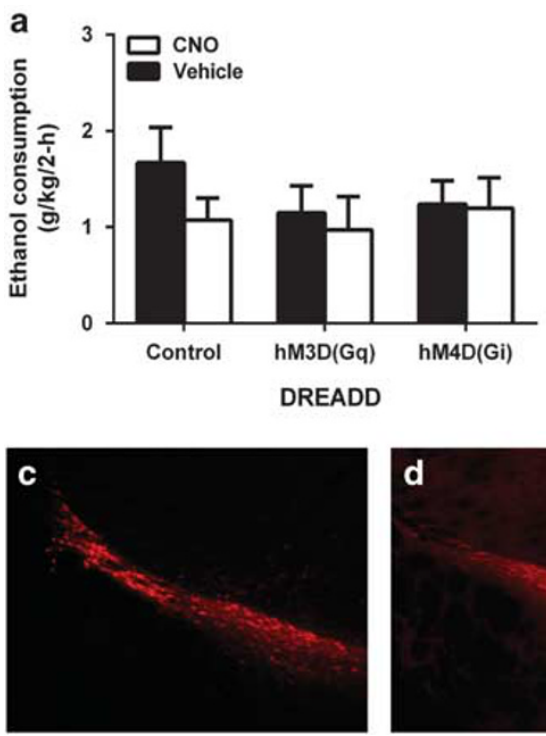
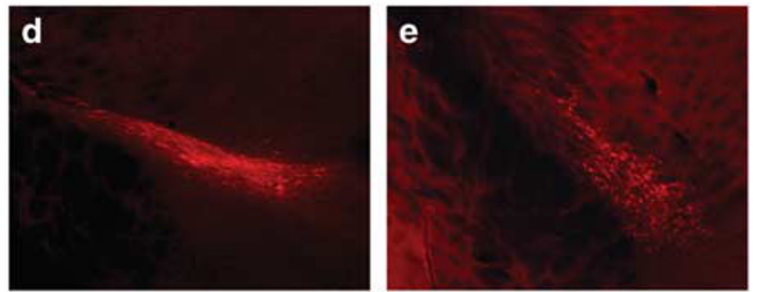

Figure 4 Results from the zona incerta (ZI) study. Two-hour 20\% (v/V) ethanol consumption (a) and food intake (b), and examples of AAV8-hSyn-DIOmcherry (Control; c), AAV8-hSyn-DIO-hM3D(Gq)-mcherry (hM3D(Gq); d), and AAV8-hSyn-DIO-hM4D(Gi)-mcherry (hM4D(Gi); e) virus expression in the $\mathrm{Zl}$. When viruses were transduced specifically in the $\mathrm{Zl}, \mathrm{CNO}$ treatment did not influence ethanol consumption or food intake in any of the virus conditions. All data are presented as mean \pm SEM.

respectively. A repeated-measures ANOVA run on sucrose intake data revealed significant main effects of $\mathrm{CNO} v s$ vehicle $(\mathrm{F}(1,10)=20.89, p=0.001)$ and virus condition $(\mathrm{F}(1,10)=31.49, p<0.001)$ effects and a significant CNO $v s$ vehicle $\times$ virus condition interaction effect $(\mathrm{F}(1,10)=118.41$, $p<0.001)$. Post-hoc tests indicated that relative to vehicle treatment, treatment with CNO significantly increased sucrose intake or reduced sucrose intake in mice expressing the AAV8-hSyn-DIO-hM3D(Gq)-mcherry or AAV8-hSynDIO-hM4D(Gi)-mcherry virus in the $\mathrm{LH}$, respectively.

\section{Mouse Cohort 3: Binge-Like Ethanol Drinking and Food Intake Following GABAergic Neuronal Manipulations in the ZI}

Two hour ethanol consumption (a) and food intake (b), and examples of virus expression (c-e) in mice with viral vectors aimed specifically at the ZI are presented in Figure 4. Repeated-measures (CNO vs vehicle $\times$ virus condition $\times$ sex) ANOVAs performed on ethanol consumption data revealed a significant $\mathrm{CNO} v s$ vehicle $\times$ sex interaction effect $(\mathrm{F}(1,14)=6.58, p=0.022)$, which reflected greater consumption of ethanol following CNO $(1.75 \pm 0.23 \mathrm{~g} / \mathrm{kg} / 2 \mathrm{~h})$ relative to vehicle $(0.92 \pm 0.25 \mathrm{~g} / \mathrm{kg} / 2 \mathrm{~h})$ in female mice but slightly lower consumption of ethanol following CNO $(1.03 \pm 0.21 \mathrm{~g} /$ $\mathrm{kg} / 2 \mathrm{~h})$ relative to vehicle $(1.17 \pm 0.23 \mathrm{~g} / \mathrm{kg} / 2 \mathrm{~h})$ in male mice. Post-hoc test comparing ethanol consumption between vehicle treatment and $\mathrm{CNO}$ treatment failed to show significant effects for male mice, though CNO-treated female mice did drink more ethanol than female vehicle-treated mice. This outcome is difficult to explain as CNO is considered to be inert (Urban and Roth, 2015). A repeatedmeasures ANOVA performed on 2-h food intake data revealed a significant main effect of $\operatorname{sex}(F(1,14)=8.35$, 
$p=0.012)$, reflecting greater consumption of food by female mice $(25 \pm 2.29 \mathrm{~g} / \mathrm{kg} / 2 \mathrm{~h})$ relative to male mice $(16.62 \pm$ $2.09 \mathrm{~g} / \mathrm{kg} / 2 \mathrm{~h}$ ). No other effects were statistically significant.

\section{Mouse Cohort 4: Wood Gnawing Behavior}

Results from the gnawing behavior experiment are presented in Figure 3c. A repeated-measures (CNO vs vehicle $\times$ virus condition) ANOVA revealed a significant main effect of both drug and virus $(\mathrm{F}(1,13)=11.064, p=0.005 ; \mathrm{F}(1,13)=5.472$, $p=0.036$, respectively) as well as a significant drug $\times$ virus interaction $(\mathrm{F}(1,13)=8.707, p=0.011)$. Post-hoc analyses revealed the group of mice expressing the AAV8-hSyn-DIO$\mathrm{hM} 3 \mathrm{D}(\mathrm{Gq})$-mCherry virus and injected CNO were significantly different from all other groups, reflecting a significant reduction of wood weight over the 2-h test that was not evident in the other groups.

\section{DISCUSSION}

The present report provides novel evidence that GABAergic neurons of the LH modulate consummatory behaviors directed at any available stimulus, including those entailing calories (food, sucrose, and ethanol), those lacking calories (saccharin, water), and those lacking biological relevance (wood). The most critical observation was that activation of GABAergic neurons in the LH induced robust consummatory behaviors, while silencing of GABAergic neurons in the LH robustly blunted consummatory behaviors. Alterations of consummatory behaviors cannot easily be attributed to secondary changes stemming from impairment of motor function, as activation or inhibition of GABAergic neurons in the LH did not significantly alter locomotor activity over a 2-h test, yet this same manipulation promoted robust changes in the intake of rewarding substances. Unexpectedly, there was a non-significant trend for reduced locomotor activity following activation of GABAergic neurons in the $\mathrm{LH}$, but as this same manipulation increased consumption, blunted activity is unlikely to be a confounding factor when interpreting consummatory behaviors.

Previous pharmacological data have established that GABA receptor signaling in the $\mathrm{LH}$ modulates consummatory behaviors (Kelly et al, 1977; Turenius et al, 2009a,b). Consistent with recent observations (Jennings et al, 2015), the present data give new insight that was not possible with a strictly pharmacological approach by providing direct evidence for a role of local GABAergic neurons in the LH in modulating consummatory behaviors. Importantly, our work provides the first evidence that LH GABAergic neurons modulate consumption of any available stimulus, regardless of caloric content or biological relevance. Interestingly, LH infusion of $\mathrm{GABA}_{\mathrm{A}}$ receptor agonists blunt, and antagonists increase, food intake (Turenius et al, 2009a,b), essentially opposite to the pattern of results presented here with regards to activation and silencing of local GABAergic transmission. These results suggest the possibility that $\mathrm{GABA}_{\mathrm{A}}$ receptors are expressed on local GABAergic neurons in the LH or on presynaptic neurons that provide excitatory input to GABAergic neurons in the LH and, viewed this way, allow pharmacological and chemogenetic data to be explained with consistency.
It is of interest to consider the possible neurocircuitry by which LH GABAergic neurons modulate consummatory behaviors. $\mathrm{MCH} / \mathrm{GABAergic}$ neurons in the $\mathrm{LH}$ project to the VTA and NAc (Bittencourt et al, 1992; DallvechiaAdams et al, 2002; Saito et al, 2001; Sears et al, 2010) and modulate consumption of natural and drug rewards (Morganstern et al, 2010; Parker and Bloom, 2012). However, as we used the same vGat-ires-cre mice used by Jennings et al (2015) and the same DREADD constructs, $\mathrm{MCH} / \mathrm{GABAergic}$ neurons are unlikely to be involved as cre is not present in $\mathrm{MCH}$ neurons of the current vGat-ires-cre mice (Jennings et al, 2015). Interestingly, a portion of NAcprojecting GABAergic neurons from the LH likely modulate NAc activity independent of neuropeptide signaling (Urstadt and Stanley, 2015). If GABAergic signaling in these pathways is necessary for the presently observed phenotypes, then one would predict that local injection of $\mathrm{GABA}_{\mathrm{A}}$ receptor agonist into the NAc would promote consumption (consistent with activation of projecting GABAergic neurons from the $\mathrm{LH}$ ), while infusion of $\mathrm{GABA}_{\mathrm{A}}$ receptor antagonist into the NAc would blunt reward consumption (consistent with silencing of projecting GABAergic neurons from the $\mathrm{LH}$ ). In fact, NAc activation of $\mathrm{GABA}_{\mathrm{A}}$ receptor signaling increases, while inhibition of $\mathrm{GABA}_{\mathrm{A}}$ receptor signaling decreases, reward (food or ethanol) consumption (Klitenick and Wirtshafter, 1988; Melon and Boehm, 2011; Nowak et al, 1998; Urstadt et al, 2013). Additional research is necessary to confirm the potential role of LH to NAc GABAergic pathways in the modulation of reward consumption. Interestingly, activation of a VTA-projecting GABAergic pathway was recently shown to increase food intake and aberrant gnawing behaviors (Nieh et al, 2015), which is also a possible pathway underlying the present observations.

It is important to consider the basic properties of the DREADDs used in the present report. Though we did not quantify the level of viral vector expression, there were apparent differences in the expression levels between the different virus groups (eg, Figure $1 \mathrm{~d}-\mathrm{f}$ ). In particular, the control virus appears to exhibit more intense florescent activity relative to the DREADD viral vectors, though the pattern or expression appears to be similar between viral vectors. However, given that behavior mapped onto the different viral vector groups as predicted (ie, increased consumption following activation of the Gq DREADD, reduced consumption following activation of the $\mathrm{Gi}$ DREADD, and no changes in consumption in the control virus group), any existing differences in viral vector expression are unlikely to account for differences in behavior between the different virus groups. In all studies that included the use of the control AAV8-hSyn-DIO-mCherry, there were no differences between groups given i.p. injection of vehicle or the $3 \mathrm{mg} / \mathrm{kg}$ dose of $\mathrm{CNO}$, verifying that $\mathrm{CNO}$ injection alone was not responsible for the observed phenotypes in animals expressing the activating AAV8hSyn-DIO-hM3D(Gq)-mCherry or silencing AAV8-hSynDIO-hM4D(Gi)-mCherry viruses. Additionally, in no cases were there significant differences between the different viral vector groups under baseline (vehicle injection) conditions, verifying that the DREADD viral vectors alone, when compared with the control virus, did not promote behavioral effects in the absence of CNO. Controlling the spread of virus transduction is difficult, and in fact in our LH study we 
observed strong virus transduction in GABAergic neurons in both the LH and ZI. Similar to the LH, much of the ZI is comprised of a dense population of GABAergic neurons (Watson et al, 2014). Although little is known about the functional role of the ZI, the subthalamus region, which includes the ZI, has been implicated in modulating consumption of natural and drug rewards (Lardeux et al, 2009). Thus we could not initially rule out the possibility that observed changes in reward consumption were modulated by GABAergic transmission in the ZI rather than, or in addition to, GABAergic transmission in the LH. To address this issue, we adjusted our infusion coordinates to a more dorsal position, thus allowing us to selectively target our viral vectors to the ZI. In this experiment, i.p. injection of CNO failed to alter food intake or ethanol consumption in a way that depended on viral vector condition. This allowed us to rule out a role for the $\mathrm{ZI}$ and to conclude with confidence that GABAergic neurons, specifically in the $\mathrm{LH}$, modulate consummatory behaviors. Finally, functional DREADD activity has been verified in numerous previous citations (Ferguson et al, 2013; Hasegawa et al, 2014; Krashes et al, 2011; Sasaki et al, 2011), and we showed that our Vgat-irescre mice expressing the AAV8-hSyn-DIO-hM3D(Gq)mCherry DREADD in the LH exhibited increased c-Fos expression and electrophysiological activity following CNO application (see Supplementary Materials, Supplementary Figures $\mathrm{S} 1$ and S2).

In summary, here we provide the first direct evidence that the LH GABAergic neurons under investigation modulate the consumption of any available stimulus, include those entailing calories (food, sucrose, and ethanol), those lacking calories (saccharin and water), and those lacking biological relevance (wood). These data indicate that, rather than specifically regulating behaviors to maintain homeostatic caloric balance, the LH GABAergic neurons under investigation modulate general consummatory behaviors, thus other upstream or parallel circuits must modulate specific motivationally driven behaviors (eg, hunger or thirst). Additional research will be necessary to identify the specific GABAergic neurocircuits that are involved.

\section{FUNDING AND DISCLOSURE}

This research was funded by NIH grant AA013573, $\mathrm{AA} 015148$, and AA022048 to TET, AA022044 to MN, AA019454, AA020911, AA011605, and MH105892 to TLK, AA022549 to EGL-G, and AA023559 to KEP. All the authors declare no conflict of interest.

\section{ACKNOWLEDGMENTS}

We thank Dr Bryan Roth and Dr Daniel Urban for providing consultation on DREADD technology and for graciously providing CNO. We also thank Ms Rhiannon Thomas for her expert assistance in developing and implementing the wood gnawing test.

\section{REFERENCES}

Anand BK, Brobeck JR (1951). Hypothalamic control of food intake in rats and cats. Yale J Biol Med 24: 123-140.
Armbruster BN, Li X, Pausch MH, Herlitze S, Roth BL (2007). Evolving the lock to fit the key to create a family of G proteincoupled receptors potently activated by an inert ligand. Proc Natl Acad Sci 104: 5163-5168.

Bittencourt JC, Presse F, Arias C, Peto C, Vaughan J, Nahon JL et al (1992). The melanin-concentrating hormone system of the rat brain: an immuno- and hybridization histochemical characterization. J Comp Neurol 319: 218-245.

Dallvechia-Adams S, Kuhar MJ, Smith Y (2002). Cocaine- and amphetamine-regulated transcript peptide projections in the ventral midbrain: colocalization with gamma-aminobutyric acid, melanin-concentrating hormone, dynorphin, and synaptic interactions with dopamine neurons. J Comp Neurol 448: 360-372.

Delgado JM, Anand BK (1953). Increase of food intake induced by electrical stimulation of the lateral hypothalamus. Am J Physiol 172: $162-168$

Ferguson SM, Phillips PE, Roth BL, Wess J, Neumaier JF (2013). Direct-pathway striatal neurons regulate the retention of decision-making strategies. J Neurosci 33: 11668-11676.

Hasegawa E, Yanagisawa M, Sakurai T, Mieda M (2014). Orexin neurons suppress narcolepsy via 2 distinct efferent pathways. J Clin Invest 124: 604-616.

Hoebel BG, Teitelbaum P (1962). Hypothalamic control of feeding and self-stimulation. Science 135: 375-377.

Hoebel BG, Thompson RD (1969). Aversion to lateral hypothalamic stimulation caused by intragastric feeding or obesity. I Comp Physiol Psychol 68: 536-543.

Jennings JH, Ung RL, Resendez SL, Stamatakis AM, Taylor JG, Huang J et al (2015). Visualizing hypothalamic network dynamics for appetitive and consummatory behaviors. Cell 160: 516-527.

Kelly J, Alheid GF, Newberg A, Grossman SP (1977). GABA stimulation and blockade in the hypothalamus and midbrain: effects on feeding and locomotor activity. Pharmacol Biochem Behav 7: 537-541.

Klitenick MA, Wirtshafter D (1988). Comparative studies of the ingestive behaviors produced by microinjections of muscimol into the midbrain raphe nuclei of the ventral tegmental area of the rat. Life Sci 42: 775-782.

Koob GF (2003). Alcoholism: allostasis and beyond. Alcohol Clin Exp Res 27: 232-243.

Koob GF, Le Moal M (2001). Drug addiction, dysregulation of reward, and allostasis. Neuropsychopharmacology 24: 97-129.

Krashes MJ, Koda S, Ye C, Rogan SC, Adams AC, Cusher DS et al (2011). Rapid, reversible activation of AgRP neurons drives feeding behavior in mice. J Clin Invest 121: 1424-1428.

Lardeux S, Pernaud R, Paleressompoulle D, Baunez C (2009). Beyond the reward pathway: coding reward magnitude and error in the rat subthalamic nucleus. J Neurophysiol 102: 2526-2537.

Leibowitz SF (2007). Overconsumption of dietary fat and alcohol: mechanisms involving lipids and hypothalamic peptides. Physiol Behav 91: 513-521.

Melon L, Boehm SL 2nd (2011). GABA(A) receptors in the posterior, but not anterior, ventral tegmental area mediate Ro154513-induced attenuation of binge-like ethanol consumption in C57BL/6J female mice. Behav Brain Res 220: 230-237.

Morganstern I, Chang GQ, Chen YW, Barson JR, Zhiyu Y, Hoebel BG et al (2010). Role of melanin-concentrating hormone in the control of ethanol consumption: region-specific effects revealed by expression and injection studies. Physiol Behav 101: 428-437.

Navarro M, Cubero I, Knapp DJ, Breese GR, Thiele TE (2008). Decreased immunoreactivity of the melanocortin neuropeptide alpha-melanocyte-stimulating hormone (alpha-MSH) after chronic ethanol exposure in Sprague-Dawley rats. Alcohol Clin Exp Res 32: 266-276.

Nieh EH, Matthews GA, Allsop SA, Presbrey KN, Leppla CA, Wichmann $\mathrm{R}$ et al (2015). Decoding neural circuits that control compulsive sucrose seeking. Cell 160: 528-541. 
Nowak KL, McBride WJ, Lumeng L, Li TK, Murphy JM (1998). Blocking $\mathrm{GABA}(\mathrm{A})$ receptors in the anterior ventral tegmental area attenuates ethanol intake of the alcohol-preferring $\mathrm{P}$ rat. Psychopharmacology (Berl) 139: 108-116.

Parker JA, Bloom SR (2012). Hypothalamic neuropeptides and the regulation of appetite. Neuropharmacology 63: 18-30.

Rhodes JS, Best K, Belknap JK, Finn DA, Crabbe JC (2005). Evaluation of a simple model of ethanol drinking to intoxication in C57BL/6J mice. Physiol Behav 84: 53-63.

Saito Y, Cheng M, Leslie FM, Civelli O (2001). Expression of the melanin-concentrating hormone $(\mathrm{MCH})$ receptor mRNA in the rat brain. J Comp Neurol 435: 26-40.

Sasaki K, Suzuki M, Mieda M, Tsujino N, Roth B, Sakurai T (2011). Pharmacogenetic modulation of orexin neurons alters sleep/ wakefulness states in mice. PLoS One 6: e20360.

Sears RM, Liu RJ, Narayanan NS, Sharf R, Yeckel MF, Laubach M et al (2010). Regulation of nucleus accumbens activity by the hypothalamic neuropeptide melanin-concentrating hormone. J Neurosci 30: 8263-8273.

Sprow GM, Rinker JA, Lowery-Gointa EG, Sparrow AM, Navarro M, Thiele TE (2015). Lateral hypothalamic melanocortin receptor signaling modulates binge-like ethanol drinking in C57BL/ 6J mice. Addict Biol.

Thiele TE, Crabbe JC, Boehm SL 2nd (2014). "Drinking in the Dark" (DID): a simple mouse model of binge-like alcohol intake. Curr Protoc Neurosci 68: 949 41-49 4912.
Thiele TE, Navarro M (2014). "Drinking in the dark" (DID) procedures: a model of binge-like ethanol drinking in nondependent mice. Alcohol 48: 235-241.

Turenius CI, Charles JR, Tsai DH, Ebersole PL, Htut MH, Ngo PT et al (2009a). The tuberal lateral hypothalamus is a major target for GABAA-but not GABAB-mediated control of food intake. Brain Res 1283: 65-72.

Turenius CI, Htut MM, Prodon DA, Ebersole PL, Ngo PT, Lara RN et al (2009b). GABA(A) receptors in the lateral hypothalamus as mediators of satiety and body weight regulation. Brain Res 1262: 16-24.

Urban DJ, Roth BL (2015). DREADDs (designer receptors exclusively activated by designer drugs): chemogenetic tools with therapeutic utility. Annu Rev Pharmacol Toxicol 55: 399-417.

Urstadt KR, Coop SH, Banuelos BD, Stanley BG (2013). Behaviorally specific versus non-specific suppression of accumbens shellmediated feeding by ipsilateral versus bilateral inhibition of the lateral hypothalamus. Behav Brain Res 257: 230-241.

Urstadt KR, Stanley BG (2015). Direct hypothalamic and indirect trans-pallidal, trans-thalamic, or trans-septal control of accumbens signaling and their roles in food intake. Front Syst Neurosci 9: 8.

Vong L, Ye C, Yang Z, Choi B, Chua S Jr, Lowell BB (2011). Leptin action on GABAergic neurons prevents obesity and reduces inhibitory tone to POMC neurons. Neuron 71: 142-154.

Watson C, Lind CR, Thomas MG (2014). The anatomy of the caudal zona incerta in rodents and primates. J Anat 224: 95-107.

Supplementary Information accompanies the paper on the Neuropsychopharmacology website (http://www.nature.com/npp) 